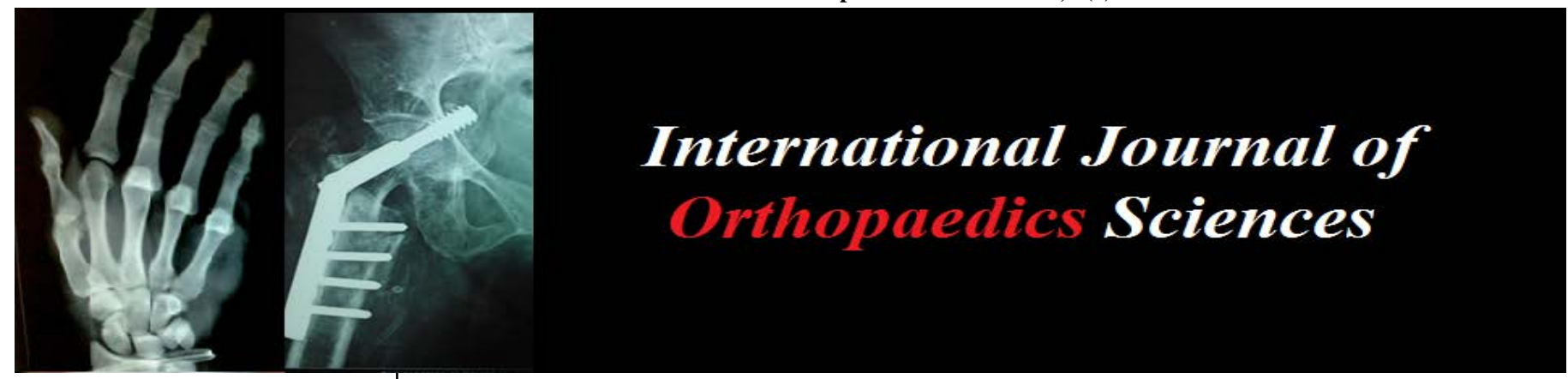

E-ISSN: 2395-1958

P-ISSN: 2706-6630

IJOS 2021; 7(4): 603-605

(C) 2021 IJOS

www.orthopaper.com

Received: 02-08-2021

Accepted: 03-09-2021

Sudhir Kumar Mahapatra Assistant Professor, Department of Orthopaedics, SCB Medical College, Cuttack, Odisha, India

Madan Mohan Sahoo

Professor, Department of Orthopaedics, PRM Medical College, Rangamatia, Baripada,

Odisha, India

\section{Udit Sourav Sahoo}

Assistant Professor, Department of Orthopaedics, SCB Medical

College, Cuttack, Odisha, India

\section{Sheetal Kaur}

Assistant Professor, Department of Radiodiagnosis, SCB Medical College, Cuttack, Odisha, India

Manoranjan Mohapatra Associate Professor, KIMS Medical College, Patia, Bhubaneswar, Odisha, India

Corresponding Author: Udit Sourav Sahoo

Assistant Professor, Department of Orthopaedics, SCB Medical College, Cuttack, Odisha, India

\section{Evaluation of asymptomatic lumbar disc herniation and endplate failure in general population and their significance in development of low backache}

\author{
Sudhir Kumar Mahapatra, Madan Mohan Sahoo, Udit Sourav Sahoo, \\ Sheetal Kaur and Manoranjan Mohapatra
}

DOI: https://doi.org/10.22271/ortho.2021.v7.i4h.2937

\section{Abstract}

Introduction: Despite being the most common cause of low back pain, there are wide variations in the pathogenesis and management of lumbar disc herniation (LDH). Previously the nucleus pulposus was being implicated for most of the symptoms, but recent papers propose the endplate failure (EPF) as the most important component of symptomatic LDH. However considering the abundance of the asymptomatic LDH in normal population, it is important to study the association of endplate failure in general population to understand it's contribution in symptomatic LDH.

Aim: To evaluate the incidence of asymptomatic LDH and EPF in normal population and note development of any low back pain in them.

Material and Methods: Adult patients presenting outdoor with complains other than present or past history of low backache were evaluated clinically and radiologically [x-ray, CT scan, MRI scan including the fat suppressed 3D fast spoiled gradient sequences (3DFSPGR)] to note status of lumbar disc and endplate. They were then, prospectively followed up for 3 years for any occurrence of backache.

Results: Twenty volunteers (13 males, 7 females) were studies from age 19-50 years (mean 33.6 \pm 10.3 ). Six volunteers (30\%) had desiccation of one or more lumbar disc and 8 volunteers (40\%) had LDH at one or more levels. However all of the LDH were broad based disc bulge. Three volunteers had cartilaginous EPF and 1 had bony EPF. None of the EPFs were associated with disc desiccation, but 2 were associated with $\mathrm{LDH}$. The presence of disc desiccations and LDH were significantly correlated to the increasing age but the EPF had no such age correlation. Subsequently 2 volunteers developed low backache.

Conclusion: Asymptomatic disc desiccation and lumbar disc bulge is fairly common. Their mere presence may not be the cause of the low backache and should be carefully considered for any surgical planning. However presence bony EPF is rare and may have some significance in development of symptomatic LDH.

Keywords: Lumbar disc herniation, bony endplate failure, cartilaginous endplate failure

\section{Introduction}

Lumbar disc herniation (LDH) is the most common cause of low backache affecting 1-5 per 1000 population per year ${ }^{[1]}$. Despite of that, there is wide variation regarding the pathogenesis and management ${ }^{[2-4]}$. The discogenic back pain is multifactorial in origin arising from mechanical compression, neurophysiological changes, ischemia, inflammatory and/or immunologic mechanisms ${ }^{[5,6]}$. Previously the nucleus pulposus was being implicated for most of the symptoms, but now the role of other structures are increasingly being recognized ${ }^{[2,3,5-9]}$. The endplate lies between the vertebral body and intervertebral disc and provides strength and nutrition to the disc ${ }^{[10-12]}$. But its junctional location predispose it to mechanical failure and early degeneration [13]. Though some previous cadaveric studies and 2 in vivo study have highlighted the role of endplate failure (EPF) in LDH none of them have delineated the extent of association and natural progression from endplate failure to symptomatic LDH. Described its significance in clinical symptomatology $[5-7,14,15,16]$. Of these 2 in vivo studies while Rajashekaran et al. have not mentioned anything regarding the cartilaginous EPF. Sahoo et al. have noted a very high incidence of asymptomatic cartilaginous EPF but have not discussed its implications on $\mathrm{LDH}^{[16]}$. 
In this present study we aim to evaluate the incidence of asymptomatic LDH and EPF in normal population and note development of any low back pain in them.

\section{Material and methods}

The present study is a prospective series of the volunteers between February 2016 and March 2018. Prior to the study an approval was taken from the ethics committee of the institute. Patients between 19-50 years of age presenting to the outdoor with symptoms other than low backache were explained about the study and those without any prior history were included in the study. They were then evaluated clinically and radiologically with $\mathrm{x}$-ray, CT scan and MRI. Exclusion criteria included prior low backache, lumbarisation of sacral or sacralisation of lumbar vertebrae, kyphoscoliosis, spinal canal stenosis, spondylolisthesis or spondylodiscitis.

During MRI, additional 3DFSPGR sequence along with the routine T1 and T2 sequences were used to study the status of the endplate (1.5T Optima GEM MRI, GE Health, United Kingdom). They were then followed every 3 months for any new onset backache, neurodeficit, active straight leg raising and Oswestry disability index (ODI) for 3 years.

All the data were recorded and analysed by SPSS 21 (IBM, New York, USA).

\section{Results}

A total of 20 cases (13 males and 7 females) with mean age of $33.6 \pm 10.3$ years were studied for a period of 3 years. Single level disc desiccation was noted in 4 cases and multilevel disc desiccation was noted in 2 cases. Of these, the most common level for disc desiccation was $\mathrm{L}_{5}-\mathrm{S}_{1}$, followed by $\mathrm{L}_{4-5}$ level. Lumbar disc herniation was noted in 8 cases; most commonly at $\mathrm{L}_{5}-\mathrm{S}_{1}$ followed by $\mathrm{L}_{4-5}$ level. All these $\mathrm{LDH}$ were posterior broad based disc bulge. Cartilaginous EPF (CEPF) was noted in a total of 3 cases. In those 3 cases, all had failure of upper endplate of $\mathrm{S}_{1}$ at $\mathrm{L}_{5}-\mathrm{S}_{1}$ disc level. One case had an additional failure of upper endplate of $\mathrm{L}_{5}$ vertebrae at $\mathrm{L}_{4-5}$ disc level. Out of the 3 cases of CEPF only one was associated with LDH. Bony EPF (BEPF) was noted in one case at upper endplate of $\mathrm{S}_{1}$ vertebra at $\mathrm{L}_{5}-\mathrm{S}_{1}$ disc level and it was associated with LDH. Two patients had Schmorl's nodes, none of which was associated with LDH. Two cases type 2 modic changes, out which one was associated with LDH. One case had asymptomatic spondylolysis without instability or backache. On subsequent follow ups 2 patients developed low backache without any radiculopathy or neurodeficit. Of this one case, a 23 years old male had CEPF at upper $\mathrm{S}_{1}$ and he developed low backache for the first time at 9 months after the initial evaluation. At the time of back pain, his visual analogue score (VAS) for pain was 4, SLR was 60 degrees and ODI was 28. He responded to conservative management of analgesics, muscle relaxant and physical therapy. The other patient, who developed pain, had the onset of symptoms at 15 months after the initial evaluation. The SLR was 80 degrees, VAS 2, ODI was 16 and it was relived with 2 weeks of conservative treatment. This was not associated with any EPF or LDH. The results are summarized in table 1.

Table 1: The results are summarized

\begin{tabular}{|c|c|c|c|c|c|c|c|c|}
\hline Serial No & Age & Sex & CEPF level & BEPF level & LDH level & Disc desiccation level & Schmorl's node level & Modic changes \\
\hline 1 & 45 & $\mathrm{M}$ & & & $\mathrm{L}_{5}-\mathrm{S}_{1}$ & $\mathrm{~L}_{5}-\mathrm{S}_{1}$ & & \\
\hline 2 & 29 & $\mathrm{~F}$ & & & & & & \\
\hline 3 & 25 & $\mathrm{M}$ & $\mathrm{L}_{4-5}, \mathrm{~L}_{5}-\mathrm{S}_{1}$ & & & & & \\
\hline 4 & 43 & $\mathrm{M}$ & & & $\mathrm{L}_{5}-\mathrm{S}_{1}$ & L5-S 1 & & \\
\hline 5 & 22 & $\mathrm{M}$ & & & L5-S 1 & & & \\
\hline 6 & 34 & $\mathrm{~F}$ & & & $\mathrm{~L}_{4-5}, \mathrm{~L}_{5-} \mathrm{S}_{1}$ & & & \\
\hline 7 & 30 & $\mathrm{M}$ & L5-S 1 & & & & & \\
\hline 8 & \begin{tabular}{|l|}
23 \\
\end{tabular} & $\mathrm{M}$ & & & & & & \\
\hline 9 & 19 & $\mathrm{~F}$ & $\mathrm{~L}_{5}-\mathrm{S}_{1}$ & & & & & \\
\hline 10 & 43 & $\mathrm{~F}$ & & & $\mathrm{~L}_{4-5}, \mathrm{~L}_{5}-\mathrm{S}_{1}$ & & & \\
\hline 11 & 24 & $\mathrm{M}$ & & & & & & \\
\hline 12 & 38 & $\mathrm{M}$ & & & & & & \\
\hline 13 & 47 & $\mathrm{~F}$ & & & & L5-S & & Type 2 \\
\hline 14 & 22 & $\mathrm{M}$ & & & & & $\mathrm{L}_{2}$ & \\
\hline 15 & 28 & $\mathrm{M}$ & & & & & & \\
\hline 16 & 48 & $\mathrm{~F}$ & & & $\mathrm{~L}_{3-4,} \mathrm{~L}_{4-5,} \mathrm{~L}_{5-\mathrm{S}_{1}}$ & L3-4, L4-5, L5-S1 & & \\
\hline 17 & 50 & $\mathrm{~F}$ & & & & & $\mathrm{~L}_{5}$ & Type 2 \\
\hline 18 & 28 & M & & & & & & \\
\hline 19 & 46 & $\mathrm{M}$ & & L5-S & $\mathrm{L}_{4-5}, \mathrm{~L}_{5}-\mathrm{S}_{1}$ & & & \\
\hline 20 & 28 & $\mathrm{M}$ & & & & L3-4, L4-5, L5-S 1 & & \\
\hline
\end{tabular}

\section{Discussion}

The present study used CT and MRI scans to identify the presence of any EPF, LDH or any other discal pathologies in asymptomatic young adults. Previous studies have implicated the EPF for symptomatic LDH, but have not addressed the casual and temporal association of EPF with LDH or low backache.

In this study, we noted the presence EPF in the normal population without any symptoms of low backache or radiculopathy with an incidence up to $8 \%$. Even in the 2 cases of CEPF who developed low backache, responded to conservative treatment and none of them worsened in subsequent follow ups so as to need surgical intervention. In our study we observed that in short term all EPF don't lead to symptomatic LDH. We also noted the presence of asymptomatic LDH up to $40 \%$. This is in accordance to the previous literature ${ }^{[17]}$. Interestingly, only one case had both $\mathrm{LDH}$ and CEPF at the same level. This questions the casual association between CEPF and LDH. However it is difficult to give any definitive comment on the BEPF, since only case of BEPF was identified in our series. We also did not find any significant association between disc desiccation, Schomrl's nodes or modic changes with EPF.

Our study has a few limitations. We have studied only 20 cases with a short duration of follow up of 3 years. A larger group with a longer follow up would have given give us a 
better statistical conclusion. However considering the cost of CT and MRI scan and poor compliance of the normal volunteers for regular checkups, it is challenging to do so. We also did not do CT or MRI during the subsequent follow ups to identify the progression of the EPF and LDH. However since the symptomatic cases responded well to conservative treatment we assume that the EPF or LDH did not worsen in those cases.

\section{Conclusion}

This study demonstrates the high incidence of asymptomatic $\mathrm{LDH}$ in the normal population. This also questions the casual association between the CEPF and the LDH. However the association between the BEPF and symptomatic LDH could not be denied from the finding of this study. These factors should be carefully considered before any surgical intervention for lumbar disc herniation.

Disclosure: This research has been funded by the AO Spine Asia Pacific research grant. One or more authors have received Fellowship Support from AO Spine Asia Pacific previously not related to this research. None of the authors have any royalties, consulting or ownership to the funding organisation. No drug or medical device related to any commercial entity was discussed in the manuscript.

\section{References}

1. Evans W, Jobe W, Siebert C. A cross-sectional prevalence study of lumbar disc degeneration in a working population. Spine 1989;14:60-4.

2. Moore RJ, Vernon-Roberts B, Fraser RD, Osti OL, Schembri M. The origin and fate of herniated lumbar intervertebral disc tissue. Spine 1996;21:2149-55.

3. Peng B, Chen J, Kuang Z, Li D, Pang X, Zhang X. Diagnosis and surgical treatment of back pain originating from endplate. Eur Spine J 2009;18:1035-40.

4. Hutton WC, Adams MA. The biomechanics of disc degeneration. Acta Orthop Belg 1987;53:143-7.

5. Schmid G, Witteler A, Willburger R, Kuhnen C, Jergas M, Koester O. Lumbar disk herniation: Correlation of histologic findings with marrow signal intensity changes in vertebral endplates at $\mathrm{MR}$ imaging. Radiology 2004;231:352-8.

6. Willburger RE, Ehiosun UK, Kuhnen C, Kramer J, Schmid G. Clinical symptoms in lumbar disc herniations and their correlation to the histological composition of the extruded disc material. Spine 2004;29:1655-61.

7. Lama P, Zehra U, Balkovec C, Claireaux HA, Flower L, Harding IJ et al. Significance of cartilage endplate within herniated disc tissue. Eur Spine J 2014;23:1869-77.

8. Yasuma T, Makino I, Saito S, Inui M. Histological development of intervertebral disc herniation. J Bone Joint Surg 1986;68:106-672.

9. Rajasekaran S, Bajaj N, Tubaki V, Kanna RM Shetty AP. ISSLS Prize winner: The anatomy of failure in lumbar disc herniation: an in vivo, multimodal, prospective study of 181 subjects. Spine 2013;38:1491-500.

10. Adams MA, Freeman BJ, Morrison HP, Nelson IW, Dolan P. Mechanical initiation of intervertebral disc degeneration. Spine 2000;25:1625-36.

11. Adams MA, Hutton WC. The effect of fatigue on the lumbar intervertebral disc. J Bone Joint Surg [Br] 1983;65:199-203.

12. Simunic DI, Robertson PA, Broom ND. Mechanically induced Disruption of the healthy bovine intervertebral disc. Spine 2004;29:972-8.

13. Gordon SJ, Yang KH, Mayer PJ, Mace AH Jr, Kish VL, Radin EL. Mechanism of disc rupture. A preliminary report. Spine 1991;16:450-6.

14. Veres SP, Robertson PA, Broom ND. Microstructure and mechanical disruption of the lumbar disc annulus. Part II: How the annulus fails under hydrostatic pressure. Spine 2008;33:2711-20.

15. Wang Y, Videman T, Battie MC. Lumbar vertebral endplate lesions: prevalence, classification, and association with age. Spine 2012;37:1432-9.

16. Sahoo MM, Mahapatra SK, Kaur S, Sarangi J, Mohapatra M. Significance of Vertebral Endplate Failure in Symptomatic Lumbar Disc Herniation. Global Spine J 2017;7(3):230-238.

17. Brinjikji W, Luetmer PH, Comstock B, Bresnahan BW, Chen LE, Deyo RA et al. Systematic literature review of imaging features of spinal degeneration in asymptomatic populations. AJNR Am J Neuroradiol 2015;36(4):811-6. 